\title{
FRIGMOBILE: APLICATIVO MÓVEL DIRECIONADO AO CONTROLE COMERCIAL E DE ESTOQUES EM REDES FRIGORÍFICAS
}

\section{FRIGMOBILE: MOBILE APPLICATION DIRECTED TO CONTROL COMMERCIAL AND INVENTORIES IN SLAUGHTERHOUSE}

Rodrigo C. Borges; Diego Freitas M. Sousa; Jucimar M. dos Santos

Instituto Federal de Educação, Ciência e Tecnologia de Goiás - Inhumas, GO. e-mail: rodrigocand@gmail.com

RESUMO - Os avanços das tecnologias de telecomunicações, redes e dispositivos portáteis, tornam a computação móvel um paradigma emergente diante sua possibilidade de interação e distribuição da informação. A computação móvel aumenta a capacidade de migrar fisicamente serviços computacionais. O computador torna-se um dispositivo sempre presente, expandindo a possibilidade de um usuário utilizar os serviços típicos encontrados nas redes. Diante do exposto, este trabalho tem como objetivo aplicar a computação móvel para o cenário de comercialização e estocagem de redes frigoríficas. A proposta é um sistema para auxiliar no controle administrativo interno e externo do setor, implementando um aplicativo móvel direcionado ao sistema operacional Android.

Palavras-chave: Android; Aplicativo; Frigoríficos.

ABSTRACT - Advances in telecommunications, networking technologies and portable devices, makes mobile computing is an emerging paradigm on its ability to interact and distribution of information. Mobile computing enhances the ability to migrate physically computational services. The computer becomes an ever present device, expanding the ability of a user to use the services found in typical networks. Given the above, this work aims at applying the mobile computing scenario for the marketing and storage of slaughterhouse. The proposal is a system to assist in internal and external administrative control of the sector, implementing a mobile application directed to the Android operating system.

Keywords: Android; Application; Slaughterhouse.

Recebido em: 10/10/2014

Revisado em: 20/11/2014

Aprovado em: 05/12/2014 


\section{INTRODUÇÃO}

A carne bovina é um alimento altamente consumido pela população brasileira e mundial. Considerada uma carne nobre, é rica em proteínas, e as carnes magras, recomendadas pelos nutricionistas para a manutenção diária de uma alimentação saudável. O consumo de carne bovina além de ser um costume brasileiro, é também verificado em diversos países, tendo um papel importante para a cadeia de exportação nacional.

Antes que esta carne esteja disponível para o consumo dentro no ambiente doméstico, ela passa por um processo logístico, que começa com a criação do gado, chegando até a industrialização da mesma, tendo como destino final o consumidor. $\mathrm{O}$ processo logístico e o controle de estoque dentro do frigorífico começa com a criação do gado de corte, criação esta que muitas vezes é feita em fazendas com abates próprios. No abate, o gado é selecionado para o corte de carne in natura ou para a industrialização. O ciclo continua com a distribuição que tem como origem os armazéns frigorificados e o destino o cliente final. (LOURENÇO, 2006)

Atualmente as redes frigoríficas têm passado por um momento competitivo, procurando melhorar a qualidade de seus produtos e serviços, além de focar na redução de custos. Tais ações têm como objetivo atingir um diferencial competitivo que garanta critérios ganhadores de pedidos e para sobrevivência do mesmo. Para atingir esse patamar, se faz necessário nos processos administrativos, uma melhora com a revisão de alguns conceitos. A continuidade no processo produtivo se baseia num bom controle, evitando pedidos com atrasos e itens faltantes que poderia causar clientes insatisfeitos com a demora do atendimento. (RODRIGUES; FERNANDES, 2009)

Neste contexto a tecnologia da informação aplicada aos processos produtivos ganha destaque. Os sistemas de informação podem ser definidos tecnicamente como um conjunto de componentes inter-relacionados que coletam (ou recuperam), processam, armazenam e distribuem informações. Nos ambientes empresariais atacadistas, a maioria dos estoques é controlada por um sistema computadorizado, devido ao grande número de cálculos rotineiros envolvidos no controle de estoques e novas tecnologias, como pontos de venda com registro de transação e leitoras de código de barras.

As empresas analisam também a melhor forma que esta operação logística aconteça com o menor custo possível. Segundo Medeiros e Moraes (2013), uma estratégia de inovação pode ter repercussão não somente sobre as atividades da firma, 
mas uma inovação tecnológica pode ser relacionada com a cadeia agroindustrial pela dinâmica de funcionamento de todo o sistema.

Assim como em processos organizacionais, o investimento em tecnologia pode agregar valores no que se refere a ganhos operacionais que se traduzem em ganhos financeiros. Um exemplo típico desta situação é a denominada computação móvel. Com a popularização dos dispositivos móveis, uma gama de recursos e aplicações pode ser utilizada em apoio gerencial, administrativo e operacional em vários segmentos.

Entre os aparelhos que propiciam a mobilidade, duas categorias são de grande importância: os smartphones e os tablets. Em sua essência, os dispositivos são computadores que possuem uma memória na qual podem ser armazenados programas ou dados, possuem unidades lógicas e aritméticas, recebem informações do usuário via teclado, muitas vezes virtual, e exibem informações via tela de alta resolução. Por consequência, surge a importância de adaptá-los ao ramo industrial e de produção como uma ferramenta essencial de apoio à logística e comercialização. Fatores como o tempo, velocidade e acessibilidade das informações fornecidas são fundamentais para a tomada de decisões.
O avanço das Tecnologias de Informação e Comunicação (TIC) aliadas ao crescente necessidade de diferenciação e adaptação dos serviços oferecidos ao mercado são implementos de apoio ao trabalho. Nesse sentido, este projeto é justificado pela ausência no mercado de uma solução móvel específica para o setor de frigoríficos que contemple funcionalidades direcionadas a comercialização e estocagem de produtos, sobretudo otimizando a gestão destas linhas.

\section{REDES FRIGORÍFICAS}

Antes de 1910, o que prevalecia no Brasil para o abastecimento local de carne eram os matadouros municipais $e$ as charqueadas primitivas. A charqueada é o nome dado no sul do Brasil, à área da propriedade rural onde se produzia o charque, galpões cobertos, onde a carne salgada era exposta para o processo de desidratação, com abastecimento precário. $\mathrm{Na}$ época apenas alguns estabelecimentos eram exceções (com instalações atualizadas para o período), similares aos pátios franceses e alemães, cujos projetos e equipamentos eram importados da Europa.

As condições estruturais no geral culminavam em condições ruins de higiene, sem a devida inspeção sanitária. Contudo as charqueadas e matadouros municipais foram importantes no abastecimento das capitais. 
Com exceção da carne salgada, a produção era para o consumo imediato, por ter um menor tempo de conservação. Os subprodutos eram mal aproveitados, dando apenas exclusividade ao couro e sebo. (FELÍCIO, 2013)

Na primeira década do século XX os responsáveis pelos Postos Veterinários eram médicos bacteriologistas, dentre os quais se destacaria o Dr. Franklin de Almeida. Sua vida foi dedicada ao profissionalismo do ensino da inspeção de carnes e defendeu duas teses sobre o tema, uma de doutorado na Faculdade de Medicina, e outra de concurso na Escola de Veterinária, ambas no Rio de Janeiro. Houve também inspetores veterinários estrangeiros como o inglês Thomaz Wood e o belga Charles Conreur, em estabelecimentos exportadores.

No fim da década de 1970, início dos anos 80, o grupo criado por Geraldo Bordon foi considerado o maior do Brasil no setor em número de funcionários, carne exportada e gado abatido. A decadência da empresa se deu nos anos 90 e o pedido de concordata é de 2000. O Grupo Bordon foi sucedido pela empresa Bertin, recentemente incorporada pela JBS Friboi. (FELÍCIO, 2013)

Atualmente as redes que seguem a legislação sobre sua área são denominamos de pecuária técnica, e os frigoríficos conhecidos como clandestinos, que existem à margem da lei, são denominados como não técnicos (Figura 1).

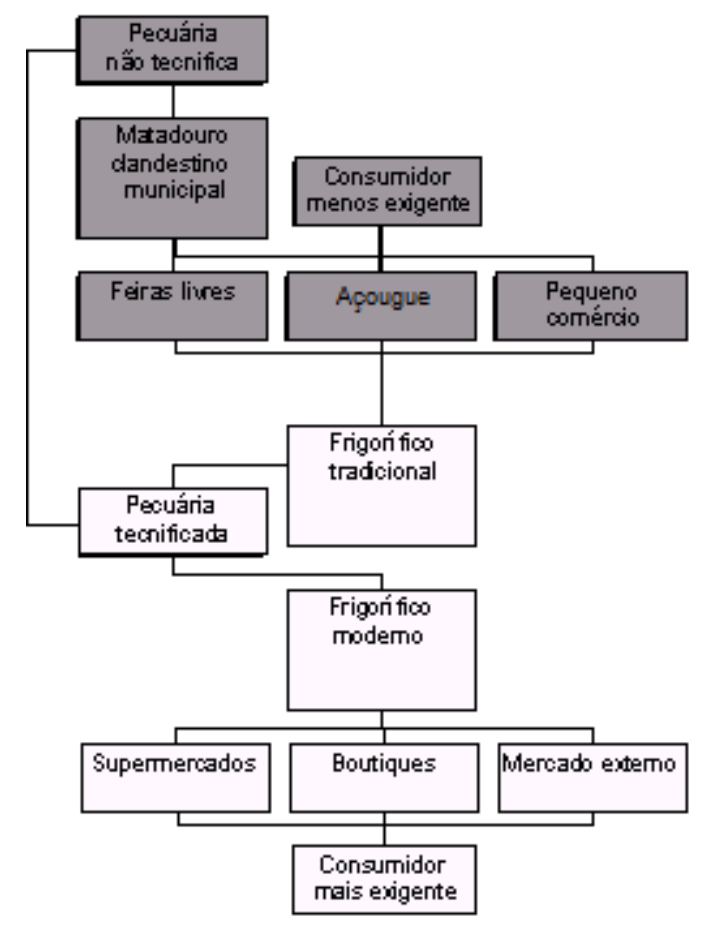

Figura 1. Pecuária Técnica e Não Técnica

Segundo Roça (2001), algumas décadas anteriores, o abate de animais era considerado uma operação tecnológica de baixo nível sem interesse acadêmico, seja com intuito para institutos de pesquisa e indústrias.

A tecnologia do abate de animais destinado ao consumo assumiu importância científica quando passou a observar os eventos que se sucedem desde a propriedade rural até o abate do animal tinham grande influência na qualidade da carne. Após o abate, as redes frigoríficas de grande porte comportam o manejo do gado, insensibilização, atordoamento, sangria, 
esfola, evisceração, refrigeração e comercialização.

\section{COMERCIALIZAÇÃO EM FRIGORÍFICOS}

Os frigoríficos de bovinos têm sua base produtiva baseada nas matérias-primas vaca ou boi. Por se tratar de um mercado de commodities, a comercialização de boi possui características que permite classificá-la como complexa. Uma dessas características é a dificuldade em conseguir lotes padronizados de animais para abate. A falta de uniformidade dos lotes é uma grande barreira para a indústria processadora de carne, uma vez que dificulta a obtenção de métricas também uniformes, exigidos pelos clientes. (CARVALHO; ALCANTARA, 2008)

Segundo Queiroz e Haddad (2009), a comercialização de animais para abate envolve o conceito de carcaça, que é o produto final do abate do bovino (descartada a cabeça, os mocotós, a cauda, o couro, as vísceras e o sangue). Os pecuaristas vendem animais vivos e os frigoríficos compram a carcaça.

O produto final restante (carcaça) é constituído de massa muscular, de estrutura óssea e a gordura e é pesada individualmente. $\mathrm{O}$ conjunto de carcaças pesadas produz o Romaneio que fornece o total (somatória) de todas as peças referentes aos animais de cada produtor. (QUEIROZ; HADDAD, 2009)
A pesagem final é convertida em arrobas e o preço a ser pago é atribuído pela cotação diária. O pagamento, no geral é realizado em 30 dias depois (aplicando-se um índice deflacionado da ordem de 3\% para pagamento a vista). Existem diferenças de preços pagos entre a arroba do boi gordo e da vaca, havendo também diferenças locais para cotações de bois inteiros $x$ castrados, rastreados ou não e com diferentes graus de terminação (gordura). (Queiroz e Haddad, 2009)

Além da descrita anteriormente, outra forma de comercialização é a venda combinada, em que o rendimento da carcaça é previamente acordado entre as partes pecuaristas versus frigorífico. Somente uma pequena parcela de produtores executa a venda combinada. Esse privilégio se explica pelo volume, qualidade, disponibilidade dos bovinos produzidos e localização da propriedade. A grande maioria dos produtores, entretanto, realiza a modalidade de comercialização descrita no início como a "venda no gancho". (QUEIROZ; HADDAD, 2009)

Em alguns lugares do Brasil, como no sul do país, a venda se processa por quilograma de peso vivo do animal, ou seja, não se aplica o conceito de arroba. $O$ animal é avaliado pelo seu peso em $\mathrm{kg}$. Apesar de haver distinção de preços entre a arroba da vaca e do boi, em boa parte do Brasil o 
consumidor adquire carne bovina, sem distinção de sexo, idade ou tipo racial. Raras exceções ficam por conta de "boutiques de carne" ou gôndolas especiais em supermercados, onde a rotulagem caracteriza $\mathrm{o}$ produto de forma mais específica.

A forma como ocorre a comercialização de carne bovina nos frigoríficos brasileiros não segue um determinado padrão, ou seja, não existe nenhuma normatização que exponha métricas necessárias para realização deste tipo de operação. Alguns optam pelo uso de tecnologias que além de facilitar o processo da venda ainda contribuem para diminuição do custo, retrabalho e tornam o processo mais eficaz; e outras ainda preferem usar meios mais primários e tradicionais.

O cenário apresentado na Figura 2 mostra todo o processo que ocorre em alguns frigoríficos desde o momento da venda até o momento da entrega da mercadoria, que na maioria dos casos são supermercados, casas de carne, atacadistas, entre outros.

Diariamente o abate dos animais é realizado. Como resultados são produzidos vários produtos para comercialização, que podem ser vendidos em forma de carcaças, recortes ou como matéria prima para produção de produtos derivados industrializados.

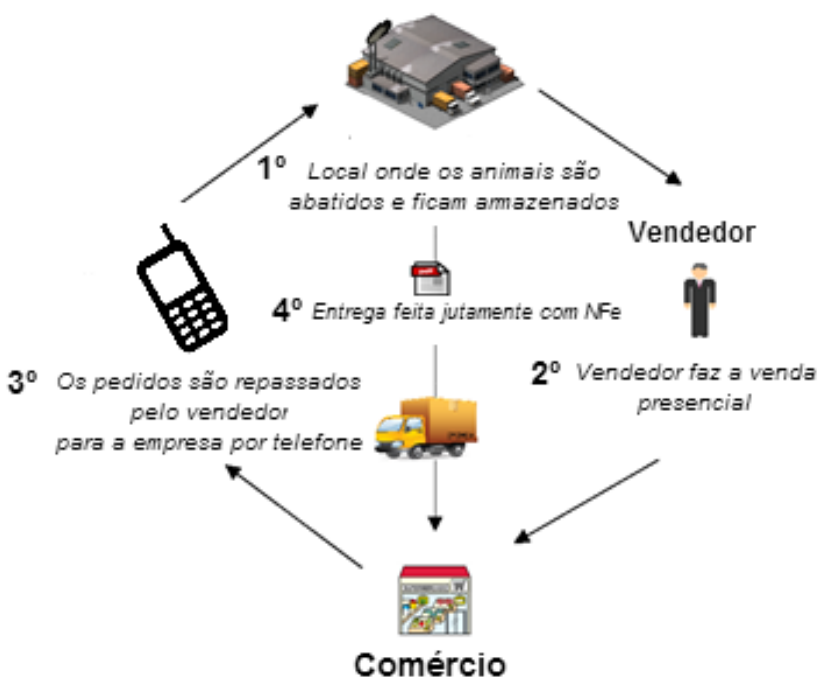

Figura 2. Representação do Processo de Comercialização do Gado

Quando se trata de lucros, o departamento de vendas recebe toda a responsabilidade de fazer com que os produtos sejam distribuídos, que o resultado seja significante e que o lucro seja visível. O vendedor vai até seu cliente, tendo em mãos papéis que possuem informações como preço, quantidade em estoque disponível para venda de cada produto; e então realiza a negociação. Logo após, o mesmo entra em contato com o frigorífico através de ligação telefônica e repassa os dados da venda realizada, como o cliente a que se destina a mercadoria, quantidade solicitada, preço combinado, horário para entrega, entre outras informações.

A partir deste momento, a empresa já tem em mãos os dados necessários para elaboração de um pedido formal, que é feito em seu sistema utilizado para o gerenciamento das informações. 
departamento de carregamento recebe diariamente um resumo de tudo que se tem para ser entregue, só aí então os produtos são separados e colocados nos caminhões e juntamente com o documento fiscal são levados aos seus destinos.

Diante dos fatos apresentados, o que se pode notar com maior frequência é uma dificuldade que o vendedor tem em realizar sua função com excelência. Por exemplo, o preço dos produtos é passado a ele em um papel, de uma hora para outra essa informações podem se tornar inconsistentes se um deles entrar em promoção e ele nem mesmo ficar sabendo. Tanto o cliente quanto o vendedor vão sair prejudicados, porque o cliente teria a oportunidade de comprar por um preço menor, mas não foi beneficiado e o vendedor teria mais chances de vender determinado produto levando em consideração a queda de preço. Outro ponto a ser analisado, seria o estoque; por exemplo, devido a uma grande demanda por determinado produto o estoque poderia se esgotar e o vendedor não tendo ciência dessa informação realizar vendas para ele.

\section{ESTRUTURA DO FRIGMOBILE}

No contexto de sistemas empresariais utilizados na atualidade, existem vários tipos de sistemas estruturados para atender as necessidades inerentes ao gerenciamento de vários departamentos internos. Todavia, quando se trata de mobilidade, vários deles deixam a desejar.

FrigMobile é uma aplicação móvel desenvolvida para a plataforma Android (LECHETA, 2013) criada com o objetivo de integrar-se a sistemas empresariais, que utilizem banco de dados PostgreSQL (OBE; HSU, 2012), através de web service modelo RESTFul (Representational State Transfer) (RUBY; RICHARDSON，2007), para atender as necessidades do departamento de vendas e estocagem. A integração se dá graças a definição de uma interface e ao uso de web service desenvolvido sob o modelo RESTful que possibilita que as informações sejam armazenadas em banco de dados relacional PostgreSQL em tempo real.

Para que as operações sejam realizadas, é necessário ter um banco de dados implantado em um servidor ligado a Internet, com permissão para receber conexões externas. O dispositivo móvel deve também ter conexão com a Internet, seja ela disponibilizada pela operadora de telefonia ou Wi-Fi.

Para o desenvolvimento do aplicativo móvel foi utilizada a IDE (Integrated Development Environment) ADT (Android Developer Tools) versão 22.3.0-887826 (ANDROID, 2014), que é uma versão do Eclipse lançada especificamente para o desenvolvimento para Android com vários recursos nativos, como plugins para 
gerenciamento de dispositivos Android virtuais, configuração de SDK (Software Developer Kit), opção visual para desenvolvimento de interfaces, dentre outras. Existe também o plugin ADT que pode ser baixado separadamente e integrado a outras IDEs Java. A vantagem de se usar o ADT (versão do Eclipse para desenvolvimento Android) é que vários problemas de incompatibilidade e instabilidade são evitados justamente por ter os recursos nativos.

As versões e configurações empregadas no cenário de implementação do FrigMobile foram:

- JRE (Java Runtime Environment) 7 update 40 (32 bits);

- JDK (Java Developer Kit) 7 update 40 (32 bits);

- Android Virtual Device (Dispositivo Virtual Android) versão 4.4;

- Biblioteca Gson versão 2.2.4;

- Sistema operacional Windows 7 Ultimate 64 bits;

- Computador com processador i5 3a geração $2.5 \mathrm{GHz}, 8 \mathrm{~GB}$ memória RAM DDR3, HD 1 TB 7200 rpm.

Objetivando criar módulos independentes, facilitando futuras manipulações de códigos ou instâncias, a estrutura do aplicativo foi distribuída entre os seguintes pacotes:

- com.br.frigmobile.activities - pacote responsável por unir todas as activities do projeto.

- com.br.frigmobile.model - pacote responsável por unir todas as classes de modelo da aplicação que tem como função representar o estado da mesma.

- com.br.frigmobile.persistencia pacote responsável por comportar a classe responsável por interagir com o banco de dados SQLite, padrão do Android e utilizado apenas para gravar a URL de hospedagem do web service.

- com.br.frigmobile.uteis - pacote que separa as classes de utilidade geral como os adapters personalizados utilizados no relatório de clientes, campo de auto complete na tela de pedido de venda, entre outros. Além disso, o pacote com.br.frigmobile.uteis comporta a classe Uteis.java que possui o método responsável por encriptar a senha de usuário, que é obtida na tela de login.

Uma vez verificadas tecnologias empregadas e módulos do FrigMobile, as 
próximas seções abordarão funcionalidades e avaliações do aplicativo.

\section{FUNCIONALIDADES DO APLICATIVO}

\subsection{Autenticação de usuários}

A primeira funcionalidade do FribMobile refere-se à autenticação de seus usuários. Para tal, o login tem como função verificar a identidade dos usuários que farão uso da aplicação. A particularidade presente na funcionalidade é a de que os usuários devem estar cadastrados no banco de dados remoto onde será feita a validação de usuário e senha. Todos os usuários com permissão de uso do aplicativo móvel devem ter o perfil de vendedor para que as informações inerentes aos clientes sejam carregadas.

Por motivos de segurança, a senha do usuário fica criptografada, tanto durante a transferência das informações entre o aplicativo e web service, quanto no armazenamento no banco de dados. A senha é convertida em um hash oferecido pelo pacote javax.security da JVM (Java Virtual Machine).

No momento em que é feito o login, é carregada uma lista com todos os clientes do vendedor. A justificativa de tal estratégia se dá com objetivo de facilitar a leitura e manipulação dessas informações nas demais funcionalidades.
Ao receber a solicitação por parte do cliente Android, o web service recebe por parâmetro username e password. A partir de então é preparada uma consulta SQL para validar no banco de dados tais informações. Em seguida, é montado um objeto com os dados obtidos no banco de dados e enviado para o dispositivo móvel.

Ao receber a resposta, o FrigMobile verifica se o atributo "codigo" do objeto é maior que zero. Caso seja, todas as demais informações do usuário são dispostas na configuração do usuário atual do aplicativo; caso contrário uma mensagem é retornada.

Cabe ressaltar que o login só pode ser realizado caso a URL do web service tenha sido informada na tela de configuração da URL. Para realização da configuração da URL do web service, é necessário autenticar com usuário administrador.

A Figura 3 mostra a tela de login do aplicativo FrigMobile. 


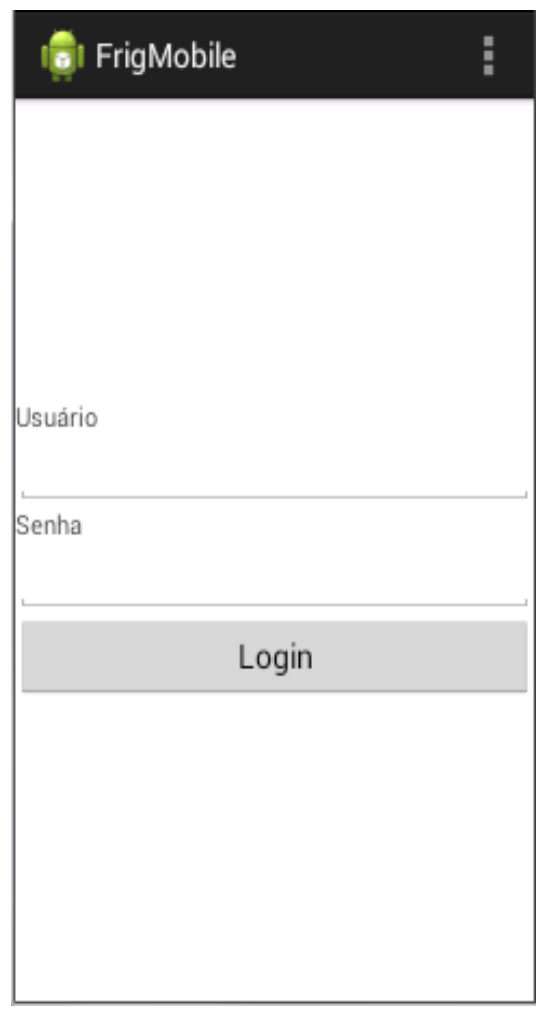

Figura 3. Autenticação FribMobile

\subsection{Relatório de clientes}

O relatório de clientes (Figura 4) tem como finalidade listar todos os clientes pertencentes ao vendedor que faz login no aplicativo móvel, FrigMobile. Possui a restrição de poder visualizar somente seus clientes, não sendo permitido fazer nenhum tipo de alteração no cadastro.

No momento em que o login é realizado, a lista de clientes é carregada e fica armazenado na sessão do usuário em um ArrayList, devido a isso a qualquer momento o relatório estará disponível para ser visualizado de forma prática e rápida. A Figura 4 mostra o ícone usado para gerar o relatório.

No momento em que o usuário executa o comando para gerar o relatório, o aplicativo móvel monta uma URL que é enviada ao web service para que o mesmo identifique o tipo de consulta que será realizada.

A URL é recebida por parâmetro pelo web service juntamente com o código do vendedor, que está consultando sua lista de clientes. É preparada uma consulta SQL para que os dados possam ser obtidos do banco de dados, montando um ArrayList resultante. O aplicativo móvel recebe os dados e faz a adaptação para que tudo seja apresentado no Adapter personalizado.

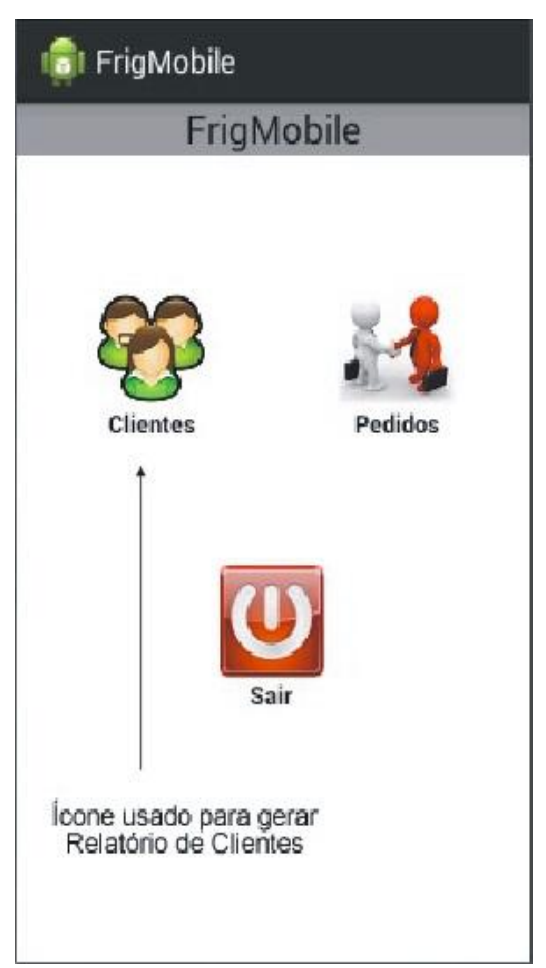

Figura 4. Menu Principal do Aplicativo

A Figura 5 mostra o relatório de Clientes, contendo o código e o nome fantasia. 


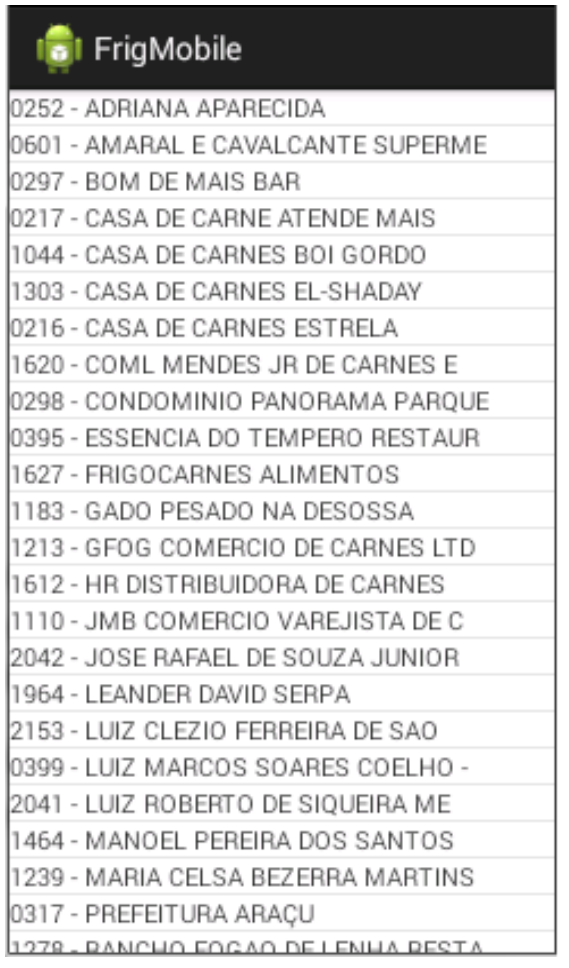

Figura 5. Relatório de Clientes

Para que os dados sejam apresentados, conforme figura, um Adapter é criado e personalizado com duas colunas, código e nome do cliente; fazendo herança à classe ArrayAdapter do pacote android.widget do Android.

\subsection{Pedido de venda}

O Pedido de Venda é a funcionalidade do FrigMobile que permite ao usuário efetuar uma venda, preenchendo as principais informações do cliente, forma de pagamento, cobrança, data de entrega e os produtos que serão vendidos.

O cliente pode ser pesquisado pelo nome fantasia, para isso basta digitar as iniciais que o campo traz as opções com nomes semelhantes, conforme mostra a Figura 6.

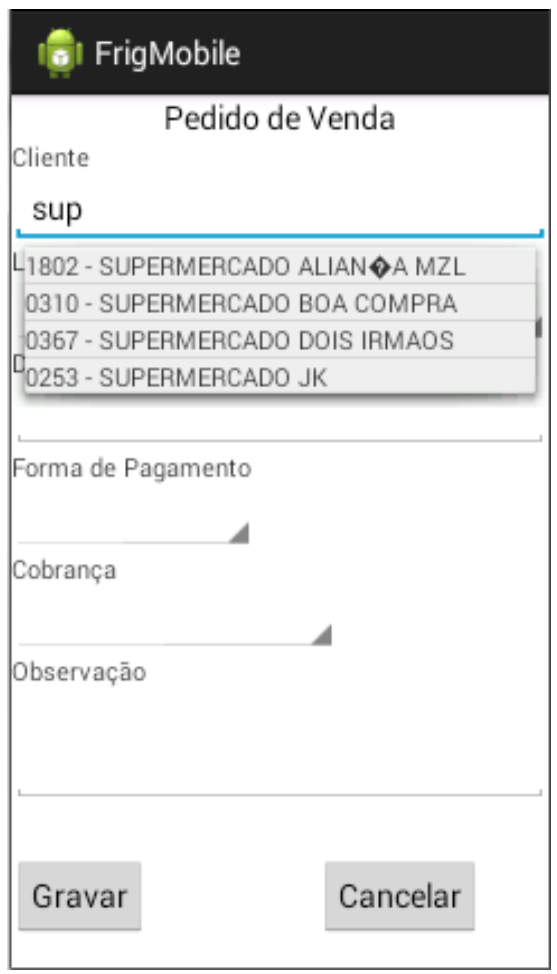

Figura 6. Pesquisa de Clientes

Após selecionar o cliente, existe um componente logo abaixo responsável por mostrar os endereços de entrega, que é chamado de Spinner. Eles são disponibilizados automaticamente ao selecionar um cliente e o primeiro da lista é automaticamente selecionado.

A forma de pagamento é representada na tela através do componente Spinner que é preenchido quando a funcionalidade Pedido de Venda é ativada. Tem como objetivo definir a forma do vencimento da venda, como por exemplo: 10 dias de prazo, 10/15 dias de prazo, etc. A Figura 7 mostra alguns exemplos de forma de pagamento. 


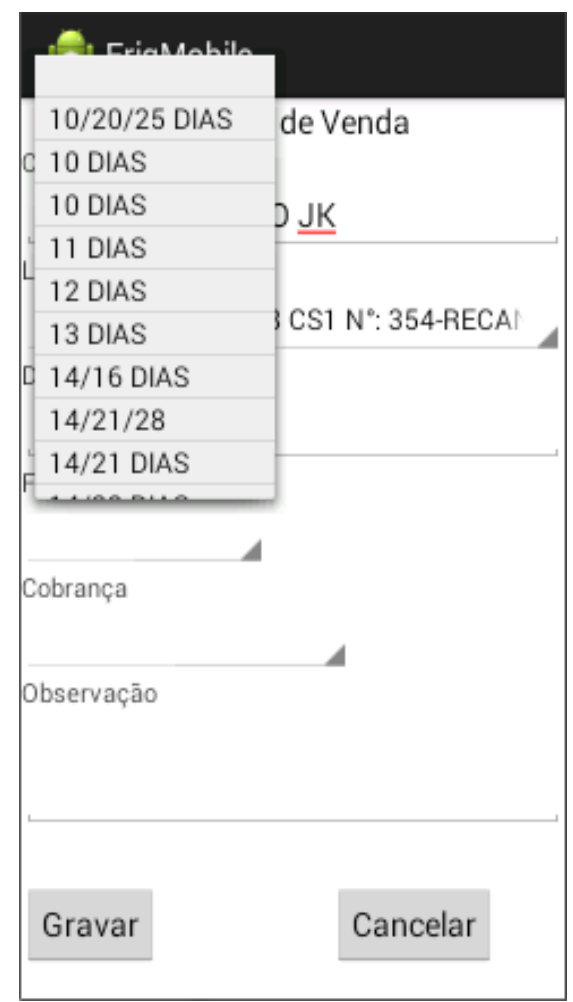

Figura 7. Formas de Pagamento

A cobrança define qual será o método utilizado para efetuar o pagamento, como por exemplo: boleto bancário, carteira, cheque, entre outros (Figura 8).

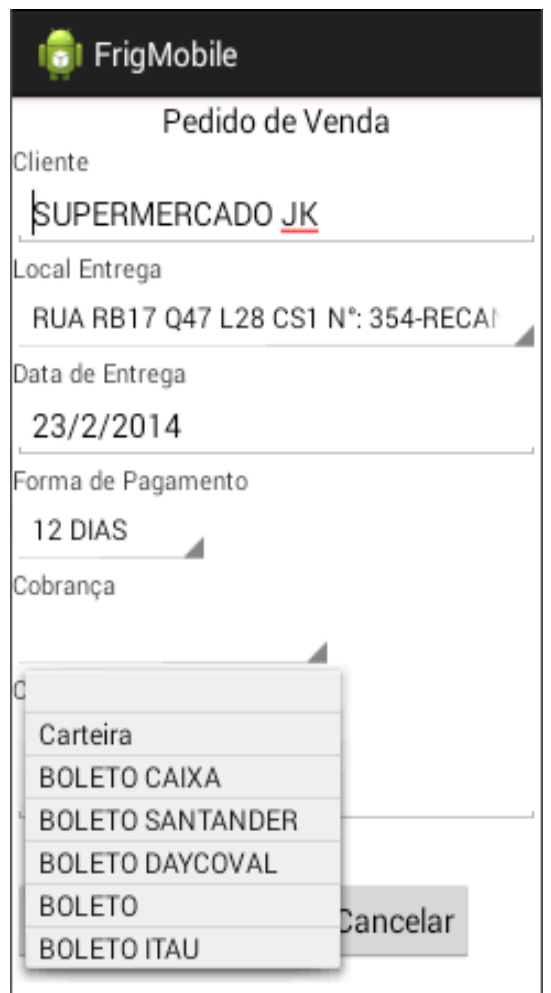

\subsection{Cadastro da URL web service}

O cadastro da URL do Web Service é feito através de uma tela criada especificamente para esta finalidade. Para ter acesso a essa configuração, é necessário fazer uma autenticação dom usuário e senha específica.

As informações adicionadas nessa tela ficam armazenadas no banco de dados do Android, o SQLite. A Figura 9 mostra a tela de configuração da URL do Web Serivce.

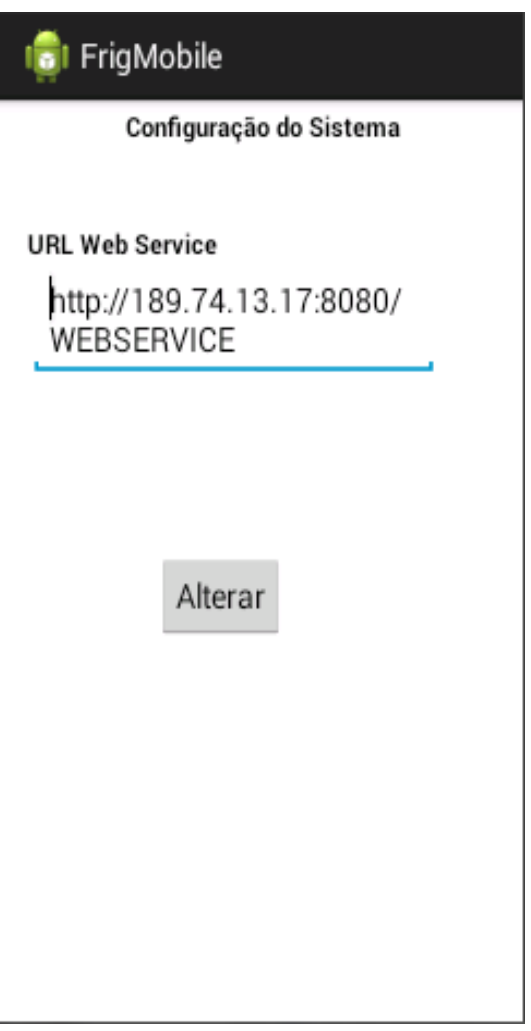

Figura 9. Tela de Configuração da URL do Web Service

Figura 8. Cobrança FrigMobile 


\section{AVALIAÇÕES}

Objetivando a avaliação da arquitetura, inicialmente um banco de dados PostgreSQL foi configurado obedecendo à interface para comunicação entre o FrigMobile e o web service. Na sequência o aplicativo móvel foi instalado em trinta e dispositivos móveis (smartphones e tablets) com Android versão 4.x para análise. Por fim, questionários foram aplicados aos usuários para teste do aplicativo.

Vale destacar que colaboradores ativos de redes frigoríficas contribuíram para o levantamento de requisitos e avaliações desta proposta.

Nos questionários aplicados, foram pautadas questões que levaram cada usuário a interpretar o programa de modo a avaliar questões referentes à sua usabilidade, sobretudo eficiência e layout. Vide resultados na Figura 10.

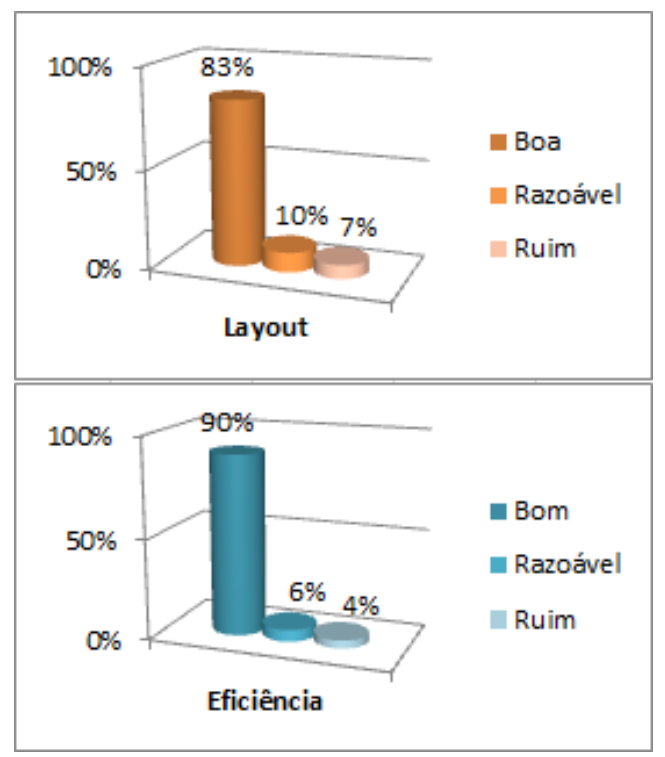

Figura 10. Avaliações quanto ao Layout e Eficiência
Considerando o layout do aplicativo, $83 \%$ avaliaram como bom, 10\% como razoável e 7\% como ruim. Quanto à eficiência do FrigMobile, $90 \%$ avaliaram como boa, $6 \%$ como razoável e $4 \%$ como ruim.

\section{CONSIDERAÇÕES FINAIS}

Com o desenvolvimento do aplicativo FrigMobile, pode-se concluir que a adoção da tecnologia móvel pode contribuir de forma significante para a evolução das unidades funcionais em uma empresa. Dessa forma é possível notar um diferencial em relação a possíveis concorrências, garantindo uma maior satisfação ao cliente.

O resultado obtido com este trabalho é um produto prático e aplicável, oferecendo possibilidades de implementação de inúmeras funcionalidades que possam aproveitar os recursos oferecidos pela plataforma Android integrada ao web service modelo Rest.

Tendo em vista as melhorias que podem ser acrescentadas ao aplicativo, como trabalhos futuros sugerem-se:

- Desenvolvimento de um front para seleção de produtos que serão inclusos no pedido com visualização da quantidade disponível em estoque;

- Envio de notificações ao vendedor responsável pela emissão do pedido 
para que o mesmo tenha ciência da conclusão da venda;

- Implementar opção para guiar o vendedor até o endereço do cliente utilizando o recurso de GPS do dispositivo móvel com plataforma Android.

- Conclusão das funcionalidades vinculadas à estocagem.

\section{REFERÊNCIAS}

ANDROID. Android developer tools. Disponível em: <http://developer.android.com/tools/help/a dt.html>. Acesso em: 03 nov. 2014.

CARVALHO, Thiago B. de; MENEZES, Shirley M.; ZEN, Sergio; ALCANTARA, Rosane L. C. Estudo do processo de compra de Boi em Frigoríficos Paulistas. In: Anais do CONGRESSO DA SOCIEDADE BRASILEIRA DE ECONOMIA, ADMINISTRAÇÃO E SOCIOLOGIA RURAL, 46th, 2008, Rio Branco. Disponível em: http://purl.umn.edu/109718. Acesso em: 10 de setembro 2014.

FELÍ́CIO, Pedro Eduardo de. O surgimento dos matadouros-frigorificos no Brasil do início do século XX. BeefPoint, 2013. Disponível em: < http://sites.beefpoint.com.br/pedrodefelicio / >. Acesso em: 03 nov. 2014.

LECHETA, Ricardo R. Google Android. 3.ed. [S.I.]: Novatec, 2013.

LOURENÇO, Regiane Cristina. A Minimização de Custos Logístico na Otimização da Capacidade de Carga de Veículos Refrigerados para a Distribuição de Carne Bovina Brasileira Dentro do Mercado Interno. 2006. Monografia (Graduação em Logística) - Faculdade de Tecnologia da Zona Leste, São Paulo.
MEDEIROS NETO, João Paulo de; MORAES FILHO, Rodolfo Araujo de. Alinhamento e maturidade na gerência de $\mathrm{TI}$ em segmento tradicional da indústria: o setor sucroalcooleiro. Revista Eletrônica e de Estratégia \& Negócios, v. 6, n. 2, 2013.

OBE, Regina O.; HSU, Leo L. PostgreSQL: up and running. 1.ed. [S.I.]: O’Reilly, 2012.

QUEIROZ, Mário Adriano Ávila; HADDAD, Claudio Maluf. Agronegocio do boi: comercialização de animais para abate. BeefPoint, 2013. Disponível em: < http://www.beefpoint.com.br/cadeiaprodutiva/dicas-de-sucesso/agronegocio-doboi-comercializacao-de-animais-para-abate51249/ >. Acesso em: 03 nov. 2014.

ROÇA, Roberto de Oliveira. Abate humanitário: manejo ante-mortem. Revista TeC Carnes, Campinas, v. 3, n. 1, p. 7-12, 2001.

RODRIGUES, Rita de Cássia; FERNANDES, Luiz Antonio. Implantação de um sistema de controle de estoques em uma empresa de pequeno porte: um estudo de caso em uma tecelagem do interior de São Paulo. In: SIMPÓSIO DE EXCELÊNCIA EM GESTÃO E TECNOLOGIA, ARTIGOS - LOGÍSTICA, 2009. Anais... [S.I.]: Associação Educacional Dom Bosco, 2009.

RUBY, Sam; RICHARDSON, Leonard. RESTful web services. 1.ed. [S.I.]: O'Reilly, 2007. 